\title{
Conceptual History, Conceptual Ethics, AND the Aims of Inquiry: A FrAMEWORK FOR THINKING ABOUT THE Relevance of the History/Genealogy of Concepts to Normative Inquiry
}

\author{
DAVID PLUNKETT
}

Dartmouth College

In this paper, I argue that facts about the history or genealogy of concepts (facts about what I call "conceptual history") can matter for normative inquiry. I argue that normative and evaluative issues about concepts (such as issues about which concepts an agent should use, in a given context) matter for all forms of inquiry (including normative inquiry) and that conceptual history can help us when we engage in thinking about these normative and evaluative issues (which I call issues in "conceptual ethics"). My aim in making this argument is to develop a schematic framework for thinking about the relationship between conceptual history and normative inquiry. The framework puts pressure on those who, often unreflectively or implicitly, dismiss the potential relevance of conceptual history to normative inquiry. At the same time, the framework can be seen as presenting a challenge to those drawn to more radical views about the relationship between conceptual history and normative inquiry. The challenge is this: if one wants a more ambitious model of the relevance of conceptual history to normative inquiry than what I provide in this paper, one needs to explain what justifies such a model.

TN On the Genealogy of Morality, Friedrich Nietzsche launches what is perhaps the most well-known attack on morality in modern philosophy. ${ }^{1}$ Famously, in making his attack, Nietzsche draws heavily on a historical account of how and why morality emerged, and what impact it has had on our lives since its emergence. One profitable way of reading this historical account-a way that will set the stage for my topic in this paper - is to understand some of Nietzsche's main historical claims as claims about concepts. Framed in this way, a core part

1. Nietzsche (1887/1994). 
of The Genealogy can be read as follows: in a context in which people use certain specifically moral concepts to make action-guiding normative claims, Nietzsche does not respond to these claims by also employing those moral concepts in question. Rather, he offers a historical account of why we started using these concepts, and of the consequences that have resulted from their use. In broad terms, Nietzsche argues that certain moral concepts (roughly, the ones that have been dominant in the modern era) emerged as part of an attempt by some people to seek vengeance on others. In turn, Nietzsche claims that the use of those concepts has supported an order that stifles human flourishing, and, in particular, the flourishing of a certain type of person for whom he has particular concern. For Nietzsche, these are not simply interesting historical observations about how some of our concepts first emerged and how they have been put to use. Rather, for him, they are observations that are meant to have normative bite. In short, they are meant to be an important part of Nietzsche's attack on the form of morality that was dominant in his era, and, in a connected vein, on the practices and assumptions of modern moral philosophy. ${ }^{2}$

Nietzsche's argument in The Genealogy (read in the way that I have outlined above) exemplifies an argumentative move that occurs throughout work in ethics and political philosophy. In basic terms, the argumentative move is this: in order to support a normative or evaluative position about the present (or future), one appeals to historical facts about the emergence or past use of concepts. This kind of argumentative move shows up in a range of important philosophical work, including, for example, in work by G.W.F. Hegel, Bernard Williams, Alasdair MacIntyre, Elizabeth Anscombe, Nicholas Wolterstorff, Raymond Geuss, Quentin Skinner, Martin Heidegger, and Michel Foucault. ${ }^{3}$

One of the striking things about the basic argumentative move that I have sketched above is this: some philosophers (e.g., Nietzsche and Geuss) make use of this move a lot. Other philosophers (e.g., Robert Nozick and Derek Parfit) hardly ever do. 4 This difference might stem just from differences in their basic philosophical temperaments, or in their philosophical interests. But, at least prima facie, there is also reason to think that philosophers working on normative and evaluative issues have a range of attitudes not just toward the particular instances of this argumentative move (such as Nietzsche's use of it in The Genealogy) but toward the merits of the argumentative move in general. Arguments that rely on this move, after all, might easily fall prey to different

2. For helpful further discussion of Nietzsche's Genealogy that resonates with my basic way of discussing it above (though not as squarely focused on issues about concepts in particular), see Leiter (2002).

3. See Hegel (1807/1977), Williams (1985), MacIntyre (1984), Anscombe (1958), Wolterstorff (2008), Geuss (2001a), Skinner (2002), Heidegger (1954/1993), and Foucault (1984C).

4. See Nozick (1974) and Parfit (1984). 
versions of the genetic fallacy, or simply involve changing the topic of discussion from a normative to a descriptive one. It is thus not hard to see why many would start with a skeptical attitude toward this argumentative move. This, then, suggests that it is worth thinking about the following general question: what should we make of this kind of argumentative move that I have sketched above? What (if anything) is there to it, and what does it take for it to be successful? Putting things in slightly more general terms, the core issue here is this: do facts about the emergence and past use of our concepts (henceforth, facts of conceptual history) matter for normative and evaluative inquiry? And, if so, how, when, and why? 5

In introducing this issue, I did so initially by reference to ethics and political philosophy. But these are not the only subareas of philosophy where we engage in normative and evaluative argument. We make normative claims (that is, claims involving should or ought, such as claims about what we should do, think, or feel) or evaluative claims (that is, claims involving value, such as claims about what is good or bad, better or worse) throughout philosophy. For example, we make claims in epistemology about which belief-forming methods are better or worse, or, relatedly, more or less justified, and claims in aesthetics about the relative merit of different works of art. The question that I have put forward is therefore one that matters for many more parts of philosophy than just ethics and political philosophy. Indeed, it is one that matters for any area of inquiry that concerns normative or evaluative issues (inquiry that I will henceforth call "normative or evaluative inquiry", or just "normative inquiry" for short).

Many philosophers who are prominent proponents of conceptual historyfor example, Nietzsche, Heidegger, and Geuss - put forward their views about conceptual history in the context of advocating for a host of controversial positions about a range of topics in philosophy. These philosophers tend to present their use of conceptual history, in one way or another, as a part of an approach to philosophy that stands in direct opposition to the main currents of the field. This can lead to the impression that, in order to think that conceptual history is, or even might be, relevant to normative inquiry, one also needs to take on a host of controversial positions on other topics in philosophy. I think this view, however, is seriously mistaken. The main reasons why conceptual history can be relevant to normative inquiry, including in potentially significant ways, can be articulated and defended within a framework that doesn't rely on a controversial stand on topics in other parts of philosophy, and which will be congenial to

5. Inquiry into the sorts of historical facts that I am interested in here is sometimes referred to as a form of "genealogical" inquiry (especially if it is done in a broadly Nietzsche-inspired or Foucault-inspired way). If one adopted this way of talking, then one might think of the facts about conceptual history as essentially facts about conceptual genealogy. However, given my aims in this paper, I avoid this way of talking. I explain why in Section 5 . 
a wide range of philosophers working within the main currents of contemporary philosophy. My goal in this paper is to make this case.

My argument in this paper is based on five basic claims. The first claim is that, for any given genuine instance of inquiry, there are internal success-conditions for that inquiry, such that the inquiry can go better or worse relative to those success-conditions. I take this to just be built into (or perhaps follow from) what it is to be an instance of inquiry, in one good stipulative sense of "inquiry". 6 The second claim is that a given inquiry can go better or worse depending on which concepts one uses in that inquiry. The third claim is that which concepts we should use in a given inquiry is (at least in part) determined by which concepts will help make that inquiry go best. The fourth claim is that there is such a thing as normative inquiry, or, put another way, that normative inquiry is a genuine form of inquiry, in the relevant, broad sense of "inquiry" that I introduced above. Finally, the fifth claim is this: the descriptive information that we get from doing conceptual history can help us make progress in figuring out which concepts will help make a given instance of inquiry go best. Put together, these claims form an argument for the potential relevance of conceptual history to normative inquiry. My argument for the potential relevance of conceptual history to normative inquiry is really thus just a special case of an argument for the potential relevance of conceptual history to inquiry more generally. What matters is just that normative inquiry is a form of inquiry.

Crucially, the conclusion of this argument is not that conceptual history in fact matters for normative inquiry, let alone that it does so in significant ways. Rather, my aim is to present a schematic framework for helping us better think about the relationship between conceptual history and normative inquiry. In assessing the degree of importance of conceptual history for normative inquiry in general, or in assessing its impact on normative inquiry into a specific normative or evaluative issue, many philosophers don't have a very clear conception of what kind of evidence would help establish things one way or another, and, thus, what it is they should be looking for in the first place, if they were to look at all. My argument in this paper-by presenting a framework for thinking about one of the core ways that conceptual history can matter for normative inquiry, including in potentially significant ways - helps provide some basic orientation in what to look for on these fronts.

6. It should be noted that if you don't like this stipulative way of talking about "inquiry", this will not matter for my core argument. Suppose one preferred a broader sense of "inquiry" such that some forms of inquiry lack the feature that I am talking about here: namely, that there are internal success-conditions for the inquiry, such that the inquiry can go better or worse relative to those success-conditions. In such a case, what I am talking about here could just be seen as one important kind of inquiry, such that many instances of inquiry have this feature but not all of them do. The rest of my argument could then be paraphrased accordingly, without loss of philosophical content. 


\section{Situating My Argument and Its Aims}

Two of the most important features of my argument are, first, its ecumenical nature and, second, its comparatively modest ambitions. In evaluating my argument, it will be crucial not only to understand that these are important features of my argument, but also to appreciate some of the reasons why they are important.

My argument is ecumenical in the following respect: it does not rest on the kinds of controversial or unorthodox philosophical theses that frequently show up in arguments that philosophers make for the relevance of conceptual history to normative inquiry. For instance, my argument doesn't take on any radical claims about the metaphysics of normativity (e.g., that some form of anti-realism or framework relativism is true about normative facts, properties, etc.), 7 the metaphysics of concepts (e.g., that concepts themselves are fundamentally social or historical entities), ${ }^{8}$ the nature of linguistic or mental content (e.g., that some strong form of externalism is true), ${ }^{9}$ or the nature of philosophy as such (e.g., that many philosophical problems can be undone by a mixture of Wittgensteinian therapeutic practice and Foucaultian genealogy). ${ }^{10}$ Some of these further theses might of course be true, and, moreover, it might of course be that the truth of some of these theses does matter for how to assess the relevance of conceptual history to normative inquiry. ${ }^{11}$ However, I take it as a distinct philosophical advantage of my argument that it rests on none of these above theses. This is for two main reasons. First, by avoiding use of these further theses, my argument takes on fewer controversial premises, thus making the argument less vulnerable to attack. Second, by proceeding in this way, we end up with a clearer and more distilled understanding of some of the main reasons why conceptual history can be relevant to normative inquiry. This distilled understanding, I claim, is one that philosophers from a range of different theoretical perspectives can grasp, and then draw on or expand on in their work in different ways, depending on their further philosophical commitments and interests.

A second important feature of my argument is that the ambitions of the ar-

7. See Geuss (2001a), Geuss (2008), Hacking (2002), and Davidson (2001).

8. Versions of this thesis show up in Geuss (2001a), Hacking (2002), Brandom (1994), Daston and Galison (2007), and Davidson (2001).

9. Semantic externalism is a major component of Sally Haslanger's work on the import of genealogy for inquiry. A central component of genealogy, as Haslanger understands it, is what I am here calling "conceptual history". See Haslanger (2005) and Haslanger (2000). See also Epstein (2010). Some form of semantic externalism is also arguably a central component of Heidegger (1927/1962) and Davidson (2001). For two of the classic statements of the broad type of externalism I have in mind here, see Burge (1979) and Putnam (1975). For helpful more contemporary discussion, see Schroeter (2008).

10. See Davidson (2001) and Hacking (2002).

11. This is something that I will return to later in this paper, when I briefly discuss (in Section 6) how certain forms of content externalism could matter here, if true. 
gument are fairly modest, at least when compared to what many are after when they make a case for the relevance of conceptual history to normative inquiry. For instance, my goal is not to overturn standard methodological assumptions in normative inquiry, nor is it to make the claim that facts about conceptual history are always an extremely important source of evidence in normative inquiry. Rather, it is a point about the possibility of conceptual history mattering to normative inquiry. This might seem that it is very easy to establish - so easy, perhaps, as to be irrelevant to the actual practice of normative inquiry. After all, isn't it possible that descriptive information about how internal combustion engines work in cars might be helpful to making progress on a wide range of issues in normative inquiry? For example, isn't it possible that such information about combustion engines could help us make progress on normative issues in ethics that prima facie have nothing directly to do with cars? One might therefore wonder if my argument is really contributing anything at all. It is. If successful, my argument in what follows does do something more than just establish that information about conceptual history is on a par with information about combustion engines (in terms of the relevance of such information to a wide range of issues in normative inquiry). In particular, my argument shows how conceptual history provides the kind of information that, given the nature of inquiry and the role of concepts within it, is the kind of information that we have good reason to suspect might matter in a range of instances of normative inquiry. How many instances of it will be relevant, and to how much of normative inquiry, isn't something that we can settle in advance. It will depend, among other things, on what the right theory of concepts is, and what conceptual history actually shows. Engaging with such issues is the task of further work. Nothing in my ecumenical framework settles how it should go.

But one might still be worried about how much my argument here really matters, given how modest my conclusions are. After all, how many philosophers explicitly deny the relevance of conceptual history to normative inquiry, let alone the potential relevance of it? Isn't all the action therefore simply figuring out exactly how much it matters, or figuring out in what specific places it does matter, or figuring out how much of our limited cognitive resources philosophers should spend studying conceptual history, as opposed to doing any number of other things? I agree that much of where the philosophical action is involves engaging with these more specific questions. But it is a mistake to think that it is where all of the important philosophical action is. To see why that is so, first consider that it is standard practice in large parts of contemporary normative inquiry (at least such inquiry that happens in the broadly Anglo-American context) to simply ignore or not worry about conceptual history, often without argument for why one is proceeding in this way. My argument gives us reason 
to think that this might very well be a mistake, and, moreover, gives us a highly ecumenical framework to help orient us in thinking about whether it actually is or is not. Against the backdrop of current practices in normative and evaluative theorizing, that by itself is an important methodological intervention to make.

Second, consider that many philosophers-especially those working within certain strands of broadly "continental" philosophy, including those drawing on work from Heidegger, Hegel, Nietzsche, and Foucault - often take it for granted that conceptual history matters for normative inquiry, and that it does so in radical or dramatic ways. My framework here can be read as a challenge of sorts to those drawn to such more radical views. The challenge is this: if one wants a more ambitious model of the relevance of conceptual history to normative inquiry than what I provide in this paper, one needs to explain what justifies such a model. One way to do that would be to reject my framework and replace it with something else-which, given how ecumenical my framework is, is going to be hard to do. Another way would be to identify what specific further premises one needs to add to my argument in order to deliver the more dramatic conclusions, and then to defend those premises. (For example, are those premises ones simply about what the actual historical facts about our concepts turn out to be? Or are they ones about the grounds of epistemic justification? Or ones about the nature of concepts?) The framework I put forward helps bring out how and why views on certain philosophical topics (e.g., the nature of concepts, or the grounds of epistemic justification), as well as the actual historical facts about our concepts, might be used to generate a more radical view than I put forward in this paper. Thus, by using my ecumenical framework as a starting point, one can begin to more clearly understand the shape of the challenges involved in defending a more radical view about the relevance of conceptual history to normative inquiry.

\section{Concepts and the Aims of Inquiry}

The first main claim of my argument is this: all forms of inquiry have internal success-conditions, such that the inquiry can go better or worse relative to those success-conditions. There are many different kinds of success-conditions that one might think are built into a given kind of inquiry (or a given token instance of that kind). In short, what those success-conditions are will depend on what the constitutive aims of that inquiry are. For my purposes in this paper, we can think of constitutive aims as follows: aims that are internal to the inquiry, in the sense that they are aims that are set by features of the inquiry qua inquiry (of the kind that it is), and not by external standards, such as what we hope to ac- 
complish with the results of an inquiry, or norms that determine whether that inquiry is one worth spending our time pursuing, all-things-considered. ${ }^{12}$

Once one grants that there are internal success-conditions for an inquiryones that explain what it would be for that inquiry to be successful on its own terms - it is difficult to resist the following thesis: which concepts one uses in a given inquiry help determine how successful or not a given inquiry is qua instance of that kind of inquiry. This brings me to the second main claim of my argument: a given instance of inquiry can go better or worse (on its own terms) depending on which concepts one uses in that inquiry.

Why think that which concepts we use matters for how well a given instance of inquiry goes? To motivate this thought, let's start with the question of what concepts are. For my purposes in this paper, we can here paint in fairly broad brushstrokes. In basic terms, I take concepts to be constituent components or ingredients of thoughts, components that help us represent the world in a certain way, or connect up thoughts in a certain way. Based on this, we can then make a distinction between an individual possessing (or having) a concept versus an individual using that concept. We can draw that distinction as follows: a) an agent has a concept when she is capable of thinking thoughts involving that concept, and b) she uses that concept when she actually thinks such thoughts. For example, an agent has the concept DOG when she is capable of thinking thoughts that represent something in the world as a dog as such (and not just, for example, as a four-legged animal of some kind). ${ }^{13}$ And she uses that concept DOG when she actually thinks thoughts using that representational capacity, such as, for example, when she thinks the thought this animal in front of me is a dog. ${ }^{14}$

With this basic understanding of concepts in hand, it is fairly straightforward to see that an instance of inquiry can go better or worse based on which concepts one uses in that inquiry. Concepts structure our thoughts and make certain thoughts possible as opposed to others. And which concepts we end up using affects which thoughts we in fact have. Since the success of inquiry depends in part on which thoughts we have, which concepts we use is part of what

12. What I have said so far helps explain what is involved in this first main claim of my argument. But it is not an argument on behalf of it. However, for my purposes here, I am just going to take this first main claim of my argument as given. This is because, as I stated in in the introduction, I take the claim here to just be built into (or perhaps to follow from) what it is to be an instance of inquiry, in one good stipulative sense of "inquiry". To give up on that idea, I think, is in effect to change the topic of conversation from the kind of activity that I am interested in here in this paper (one that I am calling "inquiry").

13. In this paper, I follow one standard convention in the literature on concepts and use smallcaps to represent concepts. On this convention, see Margolis and Laurence (1999).

14. This is, obviously, a schematic understanding of what concepts are. Different theorists will have different ways of fleshing out this schematic understanding. For my purposes here, the schematic understanding will be enough. 
helps determine how successful an instance of inquiry is. Moreover, the thoughts we have affect a whole host of other things beyond our thoughts that also matter for the success of inquiry, including, crucially, the actions we take based on our thoughts. Given these roles that concepts play in structuring our thought and action, it is hard to deny that some concepts are better than others for the purposes of a given inquiry. Importantly, this basic conclusion doesn't depend on something unique about inquiry per se. In fact, there is a more general point to be made here: for basically any project that has internal success-conditions, and which involves thought involving concepts, some concepts will be better to use than others for helping that project go well.

Some specific examples might be helpful to illustrate this claim, as well as to offer additional motivation for it. First, consider an example involving inquiry: for many parts of mathematical inquiry, it is good for an agent to have (and use) the concepts SET and NUMBER. In contrast, a gerrymandered concept that picked out all numbers, giraffes, and stoves is less good for the purposes of mathematical inquiry. Or consider an example involving a project other than inquiry: for the purposes of cooking food, it will often be helpful to have (and use) the concepts BAKE and sIMMER. In short, for many projects involving cooking, the project will generally go better if you have and use those concepts than if you do not.

One question is whether the following claim is correct: inquiry can go better or worse depending on which concepts one uses in that inquiry. Another question is what explains why exactly this claim is true. How one explains why this claim is true will depend in part on how one thinks about the successconditions of inquiry. All that I need for building my main argument is the claim itself, rather than any explanation of it. However, I want to make a brief aside here in order to discuss some different explanations of this claim that one might give, based on different models of inquiry. I do this for three main reasons. First, it helps to underscore just how ecumenical the argument thus far is. Second, it helps explain how different meta-philosophical views slot into the framework I am developing. Third, these views will also be helpful references moving forward, once I turn explicitly to discussion of conceptual history.

One straightforward model of a given instance of inquiry (which we might label as a broadly "realist" one) is to think that the inquiry aims at learning about some subset of reality, where that involves attempting to discover (and correctly represent) some part of reality that obtains independently of our inquiry into it. For our purposes here, we might also gloss this as follows: the inquiry aims at correct representation of some domain of facts. Based on this, one might then be drawn to the following view: concepts are tools that help us better learn about a part of reality and provide a true representation of it, and some tools are better to use for this purpose than others.

One could also have a more ambitious realist model, on which truth is only 
part of the goal of inquiry, and the other part involves using the concepts that match up with the objective structure of reality. Theodore Sider articulates a version of this view in Writing the Book of the World. As he puts it: "For a representation to be fully successful, truth is not enough; the representation must also use the right concepts, so that its conceptual structure matches reality's structure. There is an objectively correct way to "write the book of the world"' (Sider 2012: vii). On Sider's theory, the role of concepts here is not that they are to be assessed in an instrumental way, in terms of helping facilitate the goal of forming true beliefs, or any other goal. On Sider's view, fit between the objective structure of reality and the concepts one uses in one's theory matters independently of whatever other instrumental benefits one might get along the way by using certain concepts.

Another kind of view of inquiry one might hold ties its success to the pursuit of certain practical aims. There are different ways of fleshing out what this idea might amount to. For example, consider Bas van Fraassen's view in the philosophy of science that he calls constructive empiricism. In broad terms, according to van Fraassen, the success-conditions of scientific theories don't primarily have to do with truth. Rather, they have to do with empirical adequacy relative to our practical purposes. ${ }^{15} \mathrm{So}$, generalizing from this, we might say that one model for the success-conditions of an inquiry is this: they have to do with producing empirically adequate theories, relative to our practical purposes. Or consider here one important way of thinking about inquiry that runs from Karl Marx through the Frankfurt School (and which helps shape one way of thinking about what critical theory is, of the sort envisioned by Frankfurt School theorists such as Max Horkheimer, Theodor Adorno, Herbert Marcuse, and Jürgen Habermas). ${ }^{16}$ The idea is this: inquiry aims at helping us better understand those parts of reality that are important to understand for the purposes of the production of a better society (e.g., one that is more rational, more free, or more just). This might have to do with, for example, helping agents better understand aspects of social practices in such a way that they are better able to understand their true interests and then, in turn, actually produce social structures that promote them, or, in a related vein, emancipate themselves from certain forms of coercion or domination. ${ }^{17}$

15. As he puts it: "Science aims to give us theories which are empirically adequate; and acceptance of a theory involves as belief only that it is empirically adequate" (van Fraassen 1980: 12).

16. For a helpful collection of some of the key papers of Frankfurt School theorists, see Arato and Gephardt (1982). For a helpful collection of some of Marx's main writings, see Marx and Engels (1978).

17. For a good discussion of this way of thinking about the nature and ambitions of critical theory, especially as it is developed by Habermas, see Geuss (1981). See also Habermas (1984). For a connected way of thinking about the practical aspirations of a kind of critical social theory, see Haslanger (2012), and for one of the classic original statements of what critical theory is and aims to accomplish, see Horkheimer (1937/1975). 
The crucial point about both the van Fraassen-inspired and Frankfurt Schoolinspired ways of thinking about inquiry is this: on these models, rather than seeing certain practical upshots of our theorizing as external aims we apply to an inquiry, one can think of such aims as internal ones that are built into the constitutive aims of that inquiry itself. For theories such as these that build in more practically oriented success-conditions for inquiry, we can think of concepts as helping to contribute to (or hinder) our pursuit of certain practical ends. For example, some concepts might help us better understand the ways in which domination and oppression actually operate in our society, and thereby help us in our pursuit of a more just social order (or one that is more rational, free, etc.). ${ }^{18}$

As I said earlier, in order to develop the main line of argument here, we don't need to settle between these rival explanations of why it is that inquiry (assuming it has success-conditions of some kind) can go better or worse depending on which concepts one uses in that inquiry. Indeed, for my purposes here, we don't need to settle on any sort of explanation of that claim at all. All we need is to accept the claim.

\section{Which Concepts We Should Use in Inquiry}

The main claim of the last section was not itself a claim about what concepts we should use in inquiry. Rather, it was a claim involving an assessment of how well or poorly an inquiry can go, based on which concepts one uses in that inquiry. (It was thus not a normative claim in the narrow sense of "normative", but rather an evaluative one.) However, it is natural to think that, if true, the evaluative claim will bear on the normative question of which concepts we should use. And, indeed, in this section, I will argue that is entirely correct. More specifically, I will argue for the following claim: which concepts we should use in a given instance of inquiry is (at least in part) determined by which concepts will help make that inquiry go best.

My argument for this claim is straightforward. Suppose we have good background normative reasons for engaging in a given instance of inquiry, and, moreover, good normative reasons for trying to make inquiry successful on its own terms. ${ }^{19}$ These assumptions are ones we frequently make when engaged in inquiry, ranging from biological inquiry to normative inquiry. If we have such reasons, we thereby have normative reason to do those things that will help

18. This idea plays a central role in much of Sally Haslanger's work. See Haslanger (2012).

19. It should be noted that I will return to these kinds of assumptions in Section 7. It should also be noted that by "good normative reasons" here I mean roughly the following: sufficiently weighty normative reasons, ones that would actually make it the case that we should be engaged in a given instance of inquiry. 
make that inquiry successful, including, crucially, using those concepts that help make it successful. So, if that is right, then we should conclude as follows: which concepts we should use in a given instance of inquiry is (at least in part) determined by which concepts will help make that inquiry go best.

It should be emphasized that this is not intended as a complete account of what determines what concepts one should use in a given inquiry. Perhaps certain external norms, values, or goods should also impact what concepts one should use in a given instance of inquiry, ones that don't derive their relevance from the internal success-conditions of the inquiry. For example, suppose that we make the empirical discovery that when one uses a given concept $\mathrm{ABC}$ in pursuing biological inquiry, this reliably contributes to the suffering of millions of people. In such a case, perhaps this would lead to the following all-thingsconsidered normative judgment: one shouldn't use this concept ABC because of the empirical facts about suffering, even if using that concept nonetheless helps contribute to successful biological inquiry qua biological inquiry, given the internal norms of that inquiry. ${ }^{20}$ Nothing in my above claim about what concepts we should use in inquiry is meant to rule out that kind of all-things-considered judgment. This is why my claim is one about what (at least partially) determines what concepts we should use in inquiry, rather than one about what fully determines what concepts we should use. For the purposes of my main argument, that is all that I need.

Before moving on, I want to briefly introduce a bit of terminology to help keep track of things moving forward. In a pair of recent co-authored papers, Alexis Burgess and I have introduced the term conceptual ethics to refer to the following: normative and evaluative issues about thought and talk (Burgess \& Plunkett 2013a; 2013b). The central issues we focus on are evaluative issues about which concepts are better or worse (for use by a given agent, in a given context), and normative issues about which concepts an agent should use (in a given context). These are exactly the kinds of issues that I am discussing here. I will therefore adopt this terminology of "conceptual ethics" in what follows. It is important to stress that, in the phrase "conceptual ethics", "ethics" is meant in a very wide sense of the term. As such, Burgess and I are not taking it as given that certain kinds of values or norms (e.g., the kind that are standardly invoked in moral and political philosophy) settle the normative issues on the table. Rather, it very well might be that other kinds of norms are much more important-such as ones, for example, about conforming to the objective joints in reality (as on Sider's views on conceptual ethics in metaphysics that I sketched earlier) or the kinds that are the center of debates in normative epistemology. Nothing in the

20. For discussion of this sort of issue, see Burgess and Plunkett (2013a) and Burgess and Plunkett (2013b). I will return to this kind of issue in Section 7 of this paper. 
terminology of "conceptual ethics" is meant to privilege a position on this issue of what kinds of norms or values are relevant, or which ones are explanatorily more basic than others.

\section{Normative Inquiry Is a Kind of Inquiry}

Let's take stock of where we are. In the last section, I argued that which concepts we should use in a given instance of inquiry is (at least in part) determined by which concepts will help make that inquiry go best. This normative claim - a claim in what I am calling "conceptual ethics" - is one that applies to all kinds of inquiry. In this section, I argue that normative inquiry is a kind of inquiry, in the relevant, broad sense of "inquiry" that I have been working with in this paper. If that is right, then we can conclude the following: which concepts we should use in normative inquiry is (at least in part) determined by which concepts will help make that inquiry go best. ${ }^{21}$

As I am using the term here, "normative inquiry" refers to inquiry into normative and evaluative matters - inquiry, in short, in which we try to better understand normative issues (such as what one should do, think, or feel) or evaluative ones (such as what is better or worse). To think that normative inquiry is a form of genuine inquiry, in the relevant sense of "inquiry" that I am using in this paper, is just to think that this activity of trying to better understand normative and evaluative issues has a constitutive aim and, hence, internal success-conditions. Why accept this? Here is a basic argument in favor of doing so. Some normative judgments seem better than others qua normative judgments-perhaps because some are true whereas others are false, or because some are correct whereas others are incorrect. If you think this is correct, it supports the following claim: thinking about normative matters - which involves trying to figure out which normative judgments to make - involves internal success-conditions. Based on this, we have strong prima facie reason to think that there is such a thing as normative inquiry.

21. A note about my terminology of "kinds" of inquiry here, in talking about normative inquiry as a "kind" of inquiry. There are different levels of abstraction at which we can think of a kind of inquiry. Sometimes, when we speak of something such as "biological inquiry", "mathematical inquiry", or "normative inquiry", we speak in broad terms such that one form (or sub-kind) of normative inquiry has one constitutive aim (e.g., the aim of correctly representing the normative facts), whereas another form (or sub-kind) of it has a different constitutive aim (e.g., promoting social justice). On this way of speaking, these different forms of normative inquiry are related at some high level of abstraction-such that, crucially, we can speak meaningfully of both of them as inquiry into normative and evaluative matters-even though they differ in terms of their internal success-conditions. The view in this paper about what inquiry is, and how the constitutive aims of a given instance of inquiry are determined, is thus compatible with the idea that a broad kind of inquiry (e.g., biological inquiry, normative inquiry) is one that has sub-kinds with different kinds of internal success-conditions. 
If one wants to reject that claim, one is going to need a compelling argument to do so. One potential option here would be to appeal to a metanormative view that yields this result. But, absent significant further argument, we should resist taking such a view as a starting point. Indeed, most of the major metanormative views that are live options in contemporary philosophy, including leading versions of non-naturalistic realism, fictionalism, reductive naturalism, and quasirealist expressivism, directly support the claim I am putting forward here. Moreover, even those metanormative views that do not directly support the claim still provide us with the resources to endorse it as a further commitment. Consider the following: even if this claim is not itself entailed by a given version of metanormative expressivism as such, an expressivist could (and, I think, should) still then go on to endorse the claim (which, according to her metanormative view, might be a substantive normative claim) that some normative judgments are better than others qua normative judgments. (This would be akin to a metaethical expressivist endorsing a substantive ethical position, e.g., utilitarianism, that is not entailed by her metaethical expressivism.) Given all of this, we thus lack good reason for assuming such a skeptical view of normative inquiry by default, at least absent significant further argument.

Consider also the aims of this paper. One goal of the paper is to show philosophers already engaged in normative inquiry that they have good reason to think that conceptual history can matter for what they do. Philosophers already actively engaged in normative inquiry are ones who should be ready to grant that normative inquiry is something that can go better or worse, relative to the internal success-conditions of that inquiry.

Suppose, then, that I am right that there is such a thing as normative inquiry, such that this inquiry has internal success-conditions. When coupled with my claims from the previous sections, this yields the following result: which concepts we should use in normative inquiry is (at least in part) determined by which concepts will help make that inquiry go best. As with any other kind of inquiry (e.g., inquiry into mathematics or economics) there are different ways that this schematic thought can get implemented. It will depend on what your background views are about the aims of normative inquiry, something which is itself closely tied to your broader metanormative views (e.g., certain forms of naturalistic realism essentially spell out what those aims are, in a way that is different from expressivist views). And it will also depend on what you think concepts are, as well as your views on the foundations of conceptual ethics. But this is a big tent here. A range of philosophers, with a range of commitments about metanormative theory, the nature of concepts, and the foundations of conceptual ethics, can (and I think should) all accept the following basic claim: which concepts we should use in normative inquiry is (at least in part) determined by which concepts will help make that inquiry go best. 


\section{On the Relevance of Conceptual History to Conceptual Ethics}

We are now in a position to turn to the fifth main claim of my argument. The claim is this: the descriptive information that we get from doing conceptual history can help us make progress in figuring out which concepts will help make a given instance of inquiry go best. Since which concepts we should use in normative inquiry is (at least in part) determined by what will make that inquiry go best, this means that conceptual history matters for normative inquiry.

In order to appreciate the ways in which conceptual history can help us make progress in figuring out which concepts will help make an inquiry go best, it will be helpful to first say a bit more about what exactly conceptual history is. As I suggested in the introduction, I take facts of conceptual history to be historical facts of the following kind: a) descriptive facts about how, when, or why a given concept (or a set of concepts) first emerged in use, and b) descriptive facts about what people have done with a given concept or set of concepts after this emergence. I will call the first set of facts ones about the emergence of a given concept (or set of concepts) and the second set of facts ones about the past use of a given concept (or set of concepts). ${ }^{22}$

I now want to emphasize two important points about conceptual history as I understand it. The first point is this: just as there are different ways of doing history, and different kinds of historical explanations (e.g., evolutionary vs. teleological), there are different ways of doing conceptual history and different kinds of explanations about our use of concepts. My claims below will be general ones, and can apply to a range of forms of history and to a range of kinds of historical explanation. ${ }^{23}$

This point is tied to an important terminological choice that I am making in this paper, and which is worth flagging explicitly. Inquiry into the sorts of historical facts that I am interested in here is sometimes referred to as a form of

22. The way that one describes facts of conceptual history will interact with one's views about the metaphysics of concepts. For example, with facts about the emergence of concepts, one might describe the formation of certain concepts in history, or of new concepts coming into existence. Both Davidson (2001) and Hacking (2002) put things this way. Such language might be taken literally (which would fit with a certain view of the metaphysics of concepts on which they themselves are objects with histories). Or it might be taken more metaphorically-for example, if one thought that all concepts were abstract objects that exist independently of human activity. In such a case, facts about the emergence of concepts might then best be thought of as the emergence of the use of certain concepts by human beings, rather than new concepts themselves emerging into existence. For my purposes here, it doesn't matter which kind of view one takes about the metaphysics of concepts. Again, as with the argument throughout the paper, the point is to be ecumenical.

23. Thus, my use of the term "conceptual history" covers a wide range of work, including, for example, important components of the historical work in Skinner (2002), Tuck (1993), Koselleck (2002), Davidson (2001), Joyce (2001), Daston and Galison (2007), Moyn (2012), Geuss (2001b), Hacking (2002), and Adams (2016). 
"genealogical" inquiry. If one adopted this way of talking, then one might think of the facts of conceptual history as essentially facts about conceptual genealogy. However, for the purposes of this paper, I avoid this way of talking. This is because certain philosophers (e.g., Foucault) want to associate "genealogy" with a particular (Nietzsche-inspired) method of doing historical work, or, on a related note, with historical work done in a way that is tied to the aim of making a practical difference of a certain sort. ${ }^{24}$ I want a way to target historical facts about the emergence and past use of concepts in a way that is neutral on such issues-i.e., that allows us to talk about these historical facts regardless of how they are studied, and regardless of any practical aim one has in studying them. Therefore, for the purposes of this paper, I will stick with talking of "conceptual history" rather than "conceptual genealogy". 25

The second point that I want to emphasize about conceptual history is that a crucial aspect of conceptual history is that it is history about the concepts we employ. This can be contrasted with other kinds of history about our thoughts. For example, perhaps most importantly, consider historical facts about the content of our beliefs. Such facts are, in the first instance, ones about what we believe (e.g., that the earth is round), rather than about the concepts we employ in those beliefs (e.g., the concepts ROUND and EARTH). As with facts of conceptual history, historical facts about content are also ones that many philosophers have taken to be relevant to normative inquiry. For example, much of Nietzsche's historical work is not just about the concepts we employ but also the content of our beliefs. Or, to take a more contemporary example, consider Sharon Street's (2006) recent work on the normative significance of the history (and especially evolutionary history) of our moral beliefs (or, more generally, our normative beliefs). Street focuses on issues about content, rather than on issues about concepts. Where exactly the line is drawn between a) facts about conceptual history and b) facts about the history of the content of our beliefs is a difficult question, and one that interacts in a fairly direct way with one's theory of the nature of concepts. In what follows, I am not going to take a stand on where exactly that line is drawn or on exactly how to draw it. Rather, I am just going to assume that it can be

24. See, for instance, Foucault (1984a). For helpful critical discussion of Foucault's use of the term "genealogy" (and a discussion of Nietzsche's own use of the term), see Leiter (2002: Ch. 9). See also Geuss (1999) and Nehamas (1985).

25. It should also be noted that some philosophers and historians use the term "conceptual history" in a way that builds in important methodological and philosophical assumptions about how the history of concepts should be approached. See, for example, Koselleck (2002). This differs from my own use of the term. As I use the term "conceptual history", facts of conceptual history refer to descriptive facts about the history of our use of concepts. As I emphasized above, I remain highly ecumenical on the methodology of the study of such facts, and, thus, in no way intend my use of the term to indicate allegiance to Koselleck's approach or that of any other thinker. 
drawn in some way, and that the distinction between these two different kinds of historical facts is a meaningful one. ${ }^{26}$

In what follows, I talk in highly abstract terms and use toy examples of conceptual history, rather than discussing the details of actual examples of conceptual history. Some readers will no doubt be frustrated by this. Such readers might very well want to see concrete examples of conceptual history drawn from the existing literature in conceptual history, and then want me to explain what exactly their normative significance is. But my goal in this paper is not to do such work. Rather, my aims here are schematic. In short, I want to explain one possible way in which conceptual history can matter for normative inquirynamely, a way that involves its connections to conceptual ethics. If my argument is successful, it can be seen as an invitation for those engaged in normative inquiry to study actual instances of conceptual history to figure out how much it actually does matter. Detailed philosophical discussion of actual examples of conceptual history requires taking stands on a host of philosophical issues that I am aiming to be neutral on for the purposes of this paper (e.g., how to individuate token concepts and how to distinguish concepts from other types of things), not to mention wading into complicated historical debates. I thus stick with a high level of abstraction in what follows, and avoid actual detailed case studies.

\subsection{Facts about the Emergence of Concepts and Conceptual Ethics}

Consider the following toy example. Suppose Jennifer is using the concept PRIVACY as part of normative inquiry in political philosophy. She uses this concept a lot, but, up until now, hasn't thought much about its history. After discussion with historians, and then further studying the actual history here herself, she discovers the following facts about the emergence of her concept PRIVACY. Her concept was first brought into use by grafting together previous, somewhat disparate concepts in a hodge-podge sort of way given contingent historical pressures that are now mostly forgotten (and which Jennifer was herself unaware of until now). The explanation of why this concept came into use was not that PRIVACY was somehow responsive to some actual (normative or descriptive) division in the world (such that this concept was better than previous ones at "carving reality at its joints"). Rather, it was because of things that had nothing to do with better tracking the normative facts, or any normatively relevant part

26. That being said, even if it the distinction is a meaningful one, there is no doubt that there is a close connection between a) issues about the epistemic relevance of historical facts about the content of our beliefs and $b$ ) issues about the epistemic relevance of historical facts about concepts. I return to this point at the end of this section. 
of non-normative reality. ${ }^{27}$ We can suppose, for example, that it came into use solely because of non-rational (or perhaps irrational) aspects of contingent social practices of the time.

Discovering such historical facts would not by itself show that the concept PRIVACY is a bad one to use to accomplish the aims of normative inquiry. To show that, one needs an argument that involves premises about what the aims of normative inquiry are, and what makes a concept better or worse to use for accomplishing those aims, that go beyond the descriptive premises supplied by the history itself. Moreover, even when we supply plausible versions of those further premises, it is not obvious what the upshot of the history will be.

For the sake of concreteness, suppose we take the aims of normative inquiry to be to correctly represent the normative facts. (This is in line with the first sort of broadly "realist" model of the aims of inquiry that I introduced earlier in the paper.) It could be that even though a concept was initially brought into use for causal-explanatory reasons that had little or even nothing to do with correctly representing the normative facts, it might still be helpful for doing so. In short, a concept could have come into use for any number of reasons but still be good at playing the functional role of helping us represent the normative facts in the social/political domain. To think that this is not a possibility is to confuse historical facts about why a concept first emerged in practice with facts about what role a concept currently plays. In short, it is akin to thinking that because a chocolate cake was baked with the intention of killing someone with a chocolate allergy then that is how that cake must now be used in practice.

There is no doubt that, if one is not careful, appeals to facts about the emergence of concepts can fall prey to a version of this kind of fallacy. (The same applies to appeals to facts about the past use of concepts.) However, this does not have to be the case. For even if the facts about the emergence of a given concept cannot by themselves establish the concept's current functional role, they can at least be a helpful (albeit defeasible) indicator about this role. Moreover, our (purported) justification for using certain concepts in the present might have much to do with the (purported) history of how or why we acquired those concepts - just as our justification for holding certain beliefs might have much to do with the (purported) history of how we came to acquire those beliefs. Learning facts about conceptual history might thus undercut or defeat that justification. (Whether it does will, of course, depend not only on the details of the history but also on issues in normative epistemology.)

Return to our toy example of Jennifer and the concept PRIVACy. According

27. For an argument that many crucial concepts that we use in contemporary social/political thought have this kind of history, see Geuss (2001a). In Geuss (2001b), Geuss argues that this is true of the conceptual distinction between public and private. My use of PRIVACY in my toy example above thus connects directly to Geuss's detailed historical discussion. 
to our toy example, this concept was not initially acquired because it helped better capture the relevant subject matter at hand (roughly, the subject matter of normative social or political philosophy). If that is right, then this could serve to undercut or defeat our justification for using that concept, if we were relying on a different historical account (one according to which they were acquired for those reasons) to give us justification. More modestly, learning about the history might lead us to question whether or not the concept PRIVACY really is the best one to use to learn about and understand the normative facts in the social or political domain. In fact, learning about the history might lead us to suspect that there are very likely better ones to use, perhaps ones that are based on reforms of the existing concept, or ones that are more radical replacements of it. If all of this is on the right track, then what it shows is this: discovering facts about the emergence of concepts can matter for normative inquiry.

In sketching the case for the relevance of emergence facts to normative inquiry, I glossed things in terms of the first kind of broadly "realist" model for inquiry that I sketched in Section 2. However, my main line of argument above naturally extends to the other models I introduced there as well. Suppose the basic history of the concept PRIVACY that I have sketched is true. In addition to making us worried about whether or not we have true theories of social or political reality, this should make us worried about other things too. For example, the history should make us worried about the extent to which the concept PRIVACY is a joint-carving one that picks out important properties in the objective structure of reality (either normative reality or social reality). It should also make us worried about whether that concept picks out a property that is particularly important to keep track of, given our relevant practical aims (e.g., the achievement of a more just social order). Indeed, given the actual explanation of why the concept did emerge in use we have prima facie reason to think that the concept isn't particularly good relative to the sorts of standards we are here considering. Again, this point doesn't depend on taking a stand on exactly what those standards are. For a wide range of standards that philosophers might appeal to-connected to a wide range of views about the constitutive aims of inquiry (including those views sketched in Section 2)-the kind of history I have sketched for the concept of PRIVACY gives us prima facie reason to think that the concept isn't a particularly good one. In turn, once we have come to this conclusion, this might lead us to reform or replace the concept PRIVACY in different ways, and, perhaps, in a connected vein, give facts about what falls under our current concept less weight in our ethical and political thinking. (What we should do in more precise terms will depend on further auxiliary issues in epistemology and ethics, issues that are beyond the scope of this paper.)

Note that the mechanisms involved here are not ones in which conceptual history settles any of our normative or evaluative questions for us. Rather, the 
conceptual history in the PRIVACY case helps provide information that can be relevant to us within normative and evaluative thought. For further illustration of the basic structure here, consider again Nietzsche's work in On the Genealogy of Morality. If Nietzsche is correct, then the reason why people first started using certain moral concepts was that one group of people wanted to seek vengeance on another group, and not that they were correctly responding to anything like an objective joint in either normative or social reality. Nietzsche's story makes vivid certain possibilities that we might otherwise not appreciate. In particular, it raises questions about whether or not the concepts we use in the present play a similar role, despite initial appearances otherwise. We might wonder, for example, whether those moral concepts are still tied up with a certain kind of vengeful thinking, and wonder whether the use of these concepts is tied to what are (purportedly) bad effects on human life, while also not helping us track any important joints in reality. If that is in fact what is going on with these concepts in the present, then given a range of plausible standards for which concepts we should be using in inquiry, this gives us reason to worry about the continued use of these moral concepts in the present, especially given the import we often give them in our deliberations about what to do and how to live. ${ }^{28}$

Other things besides conceptual history might matter in a similar way. To see this, consider that Nietzsche's work might raise the kind of worries that I just sketched even if it is not historically accurate. This is because, in some cases, it might not even matter whether the story we are told about the emergence of our concepts is in fact true. Suppose we read Nietzsche's basic story from The Genealogy (sketched in broad brushstrokes in the way that I have in this paper) as a fable as opposed to an actual historical account. ${ }^{29}$ Would we still find Nietzsche's story unsettling even if we knew that the history is wrong and that the story is actually a fable? Perhaps so. In such a case, one might think of what is going on as a sort of thought experiment about the following question: if an agent were trying to accomplish bad aim $X$, how would she design a concept to help accomplish that aim? If one can tell a convincing story that the concept one might design in such a case is the same as, or even closely related to, a current concept that we employ, then this coincidence might still legitimately shake our confidence in using that concept. ${ }^{30}$

28. For extended discussion of these kinds of ideas about our specifically moral concepts, see Williams (1985).

29. It should be underscored that I am not here claiming that this would be a good exegetical account of what Nietzsche was doing. For a good overview of the interpretative problems with reading Nietzsche's work in The Genealogy as a fable rather than actual history, see Leiter (2002: esp. Ch. 9).

30. For discussion of further (purported) ways that fables about the emergence of a concept (rather than actual history) might be relevant to those using that concept in inquiry, see Williams (2002). 


\subsection{Facts about the Past Use of Concepts and Conceptual Ethics}

Let's now turn to facts about the past use of concepts, that is, descriptive facts about what people have done with a given concept or set of concepts after the emergence of that concept (or set of concepts). How might learning about such facts matter for normative inquiry?

Here, I think the case is even more straightforward than with facts about the emergence of concepts. For the sake of concreteness, let's again work with a kind of straightforward realist model of the aims of normative inquiry, wherein the aim of that inquiry is to correctly represent the normative facts. On this sort of model, concepts can be thought of in instrumentalist terms as tools that help us accomplish this aim. Now consider the following: in general, in assessing whether a tool is a good one for a specific task at hand, or whether it is deficient in some way, one of the main things we have to go on is how that tool has performed in the past. If we think of concepts as tools for helping us think and learn about a certain subject matter, then this sort of thought should apply to concepts just as much as to any other kind of tool. Insofar as we are reflective about which concepts we are using, and we then think we are justified in using such-and-such specific concepts in our thinking, one reason we will often want to give is that we think that our concepts (or closely related ones) have in fact helped us learn about and correctly represent the relevant facts in the past. Looking at conceptual history about the past use of concepts can help us uncover whether or not such beliefs are in fact justified or true. In short, we might discover that the concepts we are employing have been epistemically fruitful in the past (or not fruitful in the past). And this should bear on our assessment of how fruitful they are likely to be now, or in the future. ${ }^{31}$

I have put this point in terms of a relatively straightforward realist model of the aims of normative inquiry. But we can run a similar line of reasoning appealing to a range of other views about the aims of normative inquiry instead. Just as we can look to facts about the past use of concepts and ask "were such concepts epistemically fruitful ones?", we can also ask "did these concepts carve at the joints in the past?" or "did using these concepts help promote social justice?". Just as before, an answer to these questions should affect our assessment of whether or not these concepts are likely to do these things now, or in the future.

Of course, it might be just as hard to answer these evaluative questions about the merits of concepts in the past as it is to answer ones about the merits of our concepts in the present. If so, then looking at the conceptual history might not be a particularly important epistemic aid. But there might be any number of

31. It is worth underscoring that conceptual history can help us in this way only against some background set of normative assumptions. This sort of assessment of evidence is as dependent on background normative views as any other such assessment. 
reasons why seeing things in historical context might give us a kind of epistemic leverage that a non-historical perspective cannot. For example, think here of the kinds of practical aims that someone drawn to a form of critical theory might appeal to as part of the internal aims of inquiry, e.g., promoting a more free, just, or rational social order. If such a view of the constitutive aims of a given inquiry is right, then one way to measure the success of that inquiry is to measure whether it has in fact helped foster a more free, just, or rational society. If that is right, then a historical assessment of the practical impact of that inquiry is going to be crucial for evaluating its success, qua the kind of inquiry that it is.

Let's take stock of where we are. In this section thus far, I have argued that conceptual history can matter for helping us answer normative questions about what concepts we should use in a given instance of inquiry. Put another way, I have argued that conceptual history can be relevant to questions of conceptual ethics that matter for engaging in inquiry. In short, I have argued that both facts about the emergence of certain concepts in use as well as facts about the past use of those concepts can matter for our assessment of which concepts we should use in inquiry. The argument that I have given is a general one, and it applies to all forms of inquiry (which, I am assuming, based on my earlier argument in Section 4, includes normative inquiry). It is general in another crucial sense as well. My argument applies to both descriptive concepts and normative concepts (however that distinction between the two is drawn). Both descriptive concepts and normative concepts are ones we use in normative inquiry, and we can thus ask questions in conceptual ethics about which of both kinds of concepts we should be using in normative inquiry. The account I have given shows how conceptual history can be relevant to our normative assessment of any given concept that we use in substantive inquiry, regardless of the specific kind of concept it is. ${ }^{22}$

As I have emphasized throughout, the argument I am giving in this paper is

32. It should be noted that this point is entirely consistent with the claim that conceptual history is especially relevant to our normative assessment of certain kinds of concepts. For example, take the concepts that are expressed by so-called thick terms such as "courageous" or "jerk". In rough terms, such concepts are tied to a mix of descriptive and normative application-conditions (perhaps, though, not because of the content of those concepts themselves, but rather because of pragmatic features of their use-see, for example, Väyrynen 2013). A number of philosophers interested in the relevance of conceptual history have been particularly (even if not exclusively) interested in the history of concepts expressed by thick terms. (See, for example, Williams 1985, and Davidson 2001). There are different reasons to motivate this focus. One kind of reason is purely instrumental-conceptual history might be a particularly helpful way to get critical distance from ethically or politically objectionable thick terms, perhaps by exposing the ideological reasons why certain descriptive and normative application-conditions have become entwined. This might lead one to the following claim: conceptual history of the concepts expressed by thick terms is more important than conceptual history of other kinds of concepts, even though (as I have argued) the same basic reason why conceptual history is relevant to our normative assessment of such concepts is one that also applies to other kinds of concepts as well. 
a schematic one. My goal is to explain one core way in which conceptual history can matter for normative inquiry, and, in so doing, develop a basic framework for helping us better think about the relationship between conceptual history and normative inquiry. This framework is painted in broad brushstrokes, and it will need to be filled in in various ways to do serious philosophical work. In closing this section, I want to highlight one of the ways in which it will need to be filled in.

Issues about the epistemological relevance of historical facts about the content of our beliefs has received much more explicit philosophical discussion in recent years than parallel issues about conceptual history. ${ }^{33}$ Readers familiar with some of that recent literature will no doubt have noticed that my discussion here has not engaged with the nuances of views in that literature. Some readers might be frustrated by this. However, I take this to be a feature, rather than a bug, of my discussion. The framework that I have presented is a framework that can be filled in in different ways by people with different commitments in normative epistemology-commitments, for example, about the nature of justification, evidence, and knowledge. In moving forward with thinking about the relevance of conceptual history to normative inquiry (or inquiry of any sort), one thing one will inevitably need to do is to take on board more specific commitments about such epistemological issues than I have done here. In thinking about what those commitments should be, there are a number of relevant topics in the recent philosophical literature that are promising ones to engage with, given the close connections between the topics under discussion there and what I am talking about in this paper. One place is the growing literature on the epistemological relevance of historical facts about the content of our beliefs. Another is the burgeoning literature on the epistemic significance of disagreement, and peer disagreement in particular. ${ }^{34}$ Given my schematic goals in this paper, I do not delve into the more detailed epistemological issues that are the focus of such recent literature-issues that, of course, would be highly relevant to further, more detailed work on the relevance of conceptual history. My hope is that this paper can help provide the foundation for such further detailed work.

\section{Conceptual History, Conceptual Analysis, and Conceptual Ethics}

The argument that I have given thus far relies on the following connections: conceptual history can matter for conceptual ethics, and conceptual ethics mat-

33. For example, see Street (2006), Enoch (2011), Setiya (2012), Clarke-Doane (2012), Vavova (2014), Locke (2014), Dworkin (2011), and Schafer (2010).

34. For a helpful introduction to that topic, see Christensen and Lackey (2013). 
ters for inquiry. In this section, I want to briefly note a particular way in which conceptual history can matter for conceptual ethics, namely, via its relevance to our descriptive understanding of concepts, including the ones that we currently use as well as those that we have used in the past. In what follows, I will use the term conceptual analysis to refer to inquiry that aims to help us better understand the content of given concepts. (I use "conceptual analysis" here in a broad sense, such that, for example, it doesn't rest on a particular view of what that kind of inquiry involves or precisely what kind of understanding it yields.) ${ }^{35}$ With that terminology in hand, we can thus gloss the main point I here want to argue for as follows: conceptual history can matter for conceptual analysis, and conceptual analysis can matter for conceptual ethics.

There are two main connections here. One is a connection between conceptual history and conceptual analysis, and the other is a connection between conceptual analysis and conceptual ethics. Let's take each connection in turn, starting with the latter one.

Conceptual analysis, as I am understanding it, is distinguished from conceptual ethics in the following basic way: the former is about a descriptive issue (e.g., what is the content of the concept овјестіviту?) and the latter is about a normative issue (e.g., should I be using the concept овјестіviтy for doing work in the natural sciences?). Conceptual analysis alone therefore cannot answer our questions in conceptual ethics. More generally, it can't by itself answer our normative questions for us.

However, in helping us get clear about the content of concepts, conceptual analysis can help us in conceptual ethics. To appreciate why this is so, first consider an analogy. Suppose I am interested in normative questions about how I should fix a bicycle. It is hard to see how I should go about fixing the bicycle without having descriptive information about the thing that I am fixing. In particular, in order to fix it, it would be helpful for me to have an understanding of what it is about the bicycle that is broken. For example: Is one of the pedals missing? Or is the chain broken? Or is there a flat tire? At the same time, it would also be helpful to have an understanding of the things I am going to use to replace the broken parts. For example: If a hole in the tire is the problem that I need to fix, does the tire that I am replacing it with also have a hole in it, or is the replacement tire perhaps problematic in some other way, perhaps by being the wrong

35. The term "conceptual analysis" is sometimes used in a narrow sense to refer to a part of a specific given philosophical program - say, for instance, as a component of early-to-mid-twentiethcentury British philosophy. I do not intend to use the term that way. As I will understand the term in this paper, "conceptual analysis" refers to the project of trying to better understand the content of concepts, however the methodology and metaphysics for this is understood. My broad use of the term "conceptual analysis" here draws on Frank Jackson's basic use of the term in Jackson (1998), though it is not tied to his particular methodological views about how conceptual analysis is best approached or what import it has for philosophy. 
size for the bike? Answering these questions involves normative and evaluative thinking: it involves thinking about how the bike should be, as well as thinking about what it would be for a bike to work well. But it also involves descriptive issues about the actual bike and its potential replacement parts-e.g., issues about what the tire of the current bike is actually like, and what a potential replacement tire is actually like.

Now consider concepts. One kind of important argument in conceptual ethics revolves around the following idea: a given concept is deficient or problematic in some respect and it should therefore be revised (or replaced). ${ }^{36}$ When assessing such arguments, we should ask both a) what exactly it is about the current concept that is deficient and b) whether the revised concept (or, similarly, the replacement one) is deficient in the same way, or in some other way. Conceptual analysis alone can't answer these questions for us. But it can give us a better understanding of what certain concepts are and also what is involved in the proposed revised versions of it, or, similarly, of proposed replacement concepts. Such descriptive information can be helpful here, for exactly the same kind of reason that descriptive information about bicycle parts is relevant when fixing bicycles (or, similarly, in engineering new ones). Thus, there is a straightforward case for the relevance of conceptual analysis to conceptual ethics.

In turn, because conceptual ethics matters for inquiry (for the reasons I argued for earlier in this paper), this shows that conceptual analysis can also be helpful to inquiry. Furthermore, there are other more direct ways in which conceptual analysis might be relevant to inquiry as well. For example, here is one of them. Suppose we have background reasons for thinking that some given set of our current concepts are good ones, such that we have normative reason to continue to use them (or some revised version of them). If this is so, then engaging in conceptual analysis of those concepts might (at least in some cases) put us in a better position to actually employ them in practice. In short, we might come to better understand what it would take to fall under a given concept, and thus be in a better position to skillfully employ the concept moving forward.

Let's now turn to the second connection that I introduced earlier, the connection between conceptual history and conceptual analysis. The basic connection that I want to suggest here is this: looking at facts of conceptual history can sometimes be helpful for doing work in conceptual analysis. There are a number of different ways in which this is so. Two of the most important ones are as follows.

First, consider that one helpful way to better understand the content of given concept is to understand how that concept differs from nearby or related con-

36. For examples of this kind of argument, see Haslanger (2000) and Scharp (2013). For discussion of this kind of argument, see Burgess and Plunkett (2013a) and Burgess and Plunkett (2013b). 
cepts. For instance, one way to better understand the concept KNOWLEDGE is to appreciate how it is different than the concept JUSTIFIED TRUE BELIEF. To put it one way - a way that resonates with the basic way Frank Jackson puts it in From Metaphysics to Ethics (1998) - what matters here is how representing things one way (the way that one does when one uses the concept KNOwLEDGE) is different from another (the way that one does when one uses the concept JUSTIFIED TRUE BELIEF).

Philosophers can often identify important concepts to consider as contrasts to a target concept, and do so from the armchair without much historical perspective. Indeed, some philosophers are very good at doing this, at least for certain kinds of concepts. However, looking at conceptual history might nonetheless be of assistance here, even to such philosophers. If we situate a concept's use in historical perspective, this might help bring out which other concepts this particular concept can be usefully contrasted with for the purposes of analysis. In turn, by actually looking at those other concepts as well, this can help bring out the particular features of our target concept, for much the same reason that contrasting KNOWLEDGE with JUSTIFIED TRUE BELIEF can help. ${ }^{37}$

The second way in which conceptual history can help in conceptual analysis stems from the fact that, in many cases, the causal-explanatory reasons why agents started using a concept in the first place have to do with historically specific issues that we have now forgotten. By understanding the historical pressures that acted on the concept's initial emergence and use, we might come to appreciate parts of a concept's content that we might not be able to readily see otherwise. This is a point emphasized by, among others, Ian Hacking (2002) and Arnold Davidson (2001). The basic thought here can be put be as follows. From our current position, we might very well be able to tell that a given concept is opaque and murky in certain ways. By looking at the emergence facts about this concept, we can come to better appreciate what forces made it such that we started to use this specific concept. Understanding these forces can help illuminate why the concept has certain strange features to its content that might not make much sense to us now - features which, once we understand how and why this concept started to be used for historically specific reasons, no longer seem as unexpected. In short, the basic idea is this: awareness of such historical facts can help one be attuned to aspects of a concept's content that one might otherwise overlook or fail to adequately appreciate.

It is important to be clear here about what role I have claimed conceptual

37. This idea is at the core of the strategy pursued by Daston and Galison (2007). In short, Daston and Galison argue that the concept овјестіviту that is operative in the modern natural sciences is importantly different from other concepts that have also served to play a central regulatory role scientific practice, and that thinking about those differences can help us better understand овјестіviту itself. 
history can play in conceptual analysis. A strong thesis that one might have is that the only way to successfully accomplish conceptual analysis, in all cases, for all concepts, involves looking at certain facts of conceptual history. I have made no such claim. Instead, all that I have claimed is that doing conceptual history can sometimes help in the project of conceptual analysis. I have not claimed that it always can. And I have certainly not claimed that it is something necessary to do in order to successfully carry out a conceptual analysis of any given concept. There might be certain concepts-or certain epistemic situations we find ourselves in - that make conceptual history particularly relevant to conceptual analysis. But that is a topic for another discussion.

In this section, I have argued that conceptual history can matter for conceptual ethics in part because conceptual history can matter for conceptual analysis. Given my earlier arguments for why conceptual ethics matters for inquiry (including normative inquiry), this then spells out a particular way that conceptual history can matter for those engaged in normative inquiry.

Before moving on, I want to pause here to note a possible further connection between conceptual history and conceptual analysis. Many contemporary philosophers (owing largely to the tremendous impact of work done by Hilary Putnam, Tyler Burge, and Saul Kripke) are drawn to some sort of externalism about mental or linguistic content, such that facts about the basic content of our thoughts (or our linguistic statements) depend on the external world in a direct way, regardless of the individual intentions of a speaker or other facts about her "internal" mental states..$^{38}$ There are different ways of fleshing out what this basic thesis might amount to. For my purposes here, I don't need to take a stand on how to best understand content externalism, or even whether some form of it is true. Rather, we can simply note the following. One way to develop a form of content externalism about concepts would be to hold that facts about the history of a concept's use are partly determinative of the current content of a concept. If such a view turned out to be correct, it would provide another, more direct way in which conceptual history would be relevant to conceptual analysis. 39

\subsection{Thinking Otherwise}

With these connections between conceptual history, conceptual analysis, and conceptual ethics in mind, I now want to briefly turn to another way in which conceptual history can be relevant to conceptual ethics.

Consider again conceptual analysis. When we analyze a concept, this concept need not be one that we currently use. Instead, for example, it might be one

38. See Putnam (1975), Burge (1979), and Kripke (1980).

39. For further discussion of the links between content externalism and conceptual history, see Haslanger (2005), Haslanger (2000), and Epstein (2010). 
that people (perhaps we ourselves) have used in the past. As I discussed above, better understanding such concepts can help us better understand the concepts we in fact use in the present. But that understanding can matter in a more direct way as well: looking at these concepts from the past might help us recognize that a concept other than our current one could potentially play the same (or a similar) functional role in our practices that ours does. Showing the use of such other concepts in history should itself be thought of as one of the key contributions that conceptual history can make to conceptual ethics. In showing how others in history used certain concepts to play a functional role now played for us by a different concept, conceptual history can show that our use of a given concept to play a given functional role is something that could be otherwise. In other words, looking at conceptual history can de-naturalize our use of a concept that we (perhaps unconsciously) take to be the only one that we could possibly be using to play a given functional role in our thought or practice. $4^{\circ}$

That being said, I think it is important to proceed here with caution. One might tell an advanced physicist that a lot of people in the world have views on physics much different from her own. Yet this sheer diversity of views should not give her much pause-nor should the fact that most people remain stuck using folk concepts of physics rather than those provided by the best current work in physics. After all, a lot of people have mistaken views in physics and, moreover, fail to use the best concepts for doing physics. This is especially true when one thinks about views in physics that people have had throughout history. Thus, showing someone that there are a diversity of concepts that one might use for the same role (e.g., such-and-such role in regulating our sexual practices) is, in principle, not necessarily any more normatively relevant than showing the physicist the data about the diversity of views that people have in physics.

If this is so, then, when addressing the normative question of which concept we should use for a certain functional role in our current practices, we should not be primarily concerned with which concept has always played the role (if any has), or relatedly, with how long a concept has played that role for. Rather, we should primarily be concerned with which concept we have most normative reason to employ. In many cases, it might well be that we have good normative reason to employ a concept that has only recently started to play a given functional role in our practices.

Thus, looking at the conceptual history should only put pressure on us to

40. This broad theme is an important component of much of the work of Michel Foucault, including in work such as Foucault (1978), Foucault (1966/2002), and Foucault (1984C). For connected discussion, see Davidson (2001) and Hacking (2002). In a different theoretical vein, this theme is also an important part of work done by such historians of political thought as Quentin Skinner and Richard Tuck. See Skinner (1978), and Tuck (1993). 
actually consider thinking otherwise not just when it shows the possibility of thinking otherwise, but when it casts relief on our current views about what concepts we have most reason to employ. In other words, what is going to be important here for conceptual ethics is not just that we discover that there is a choice about what concepts to use that we perhaps did not previously see. Rather, what is going to be important is that we discover that this choice exists and that it is a choice that is worth deliberating about seriously. This can happen, for instance, when our looking at conceptual history furnishes us with a range of alternative concepts that we weren't paying attention to beforehand but that we have normative reason to take seriously as alternatives. We might begin to appreciate that we have such reason once we are presented with these concepts, the history of why others have used these concepts before us, and the history of why these concepts fell out of use in the present. ${ }^{41}$

It should here be noted that other kinds of non-historical inquiry might be used to put pressure on us to consider thinking otherwise in a similar way-e.g., anthropological or sociological work on which concepts others in the present are using. How much putting things in explicitly historical perspective matters will depend on a host of further issues. These further issues include how historically conditioned our current concepts actually are, whether certain kinds of externalism about conceptual content turns out to be true (e.g., ones according to which historical facts about the past use of concepts play a major role in determining that content), and the degree to which (purported) facts about history play a role in the justifications we have for why we currently use certain concepts rather than others. My framework leaves open the possibility that all of the roles that historical facts about concepts can play in normative inquiry could also be played (at least in principle) by non-historical facts about concepts as well, and perhaps could often be better played by non-historical facts. Connected to this, my framework leaves open questions about which tools will be most useful when; for example, perhaps doing work on conceptual history will be more fruitful in certain social or historical contexts than others. Or perhaps historical inquiry will be more fruitful for creatures like us, given contingent features of our psychologies, when certain kinds of issues are at play. Some views about

41. In thinking about whether or not we have normative reason to take seriously alternative concepts, a further issue will be questions about how available those past concepts are for us in the present. For example, it might be good if we could use a given concept, but this option might be effectively closed to us at this point in history - perhaps because of the way this concept is situated within a more general conceptual scheme that is radically different from our own. In short, some concepts might simply be ones that are not historically possible options for us, in some relevant sense of "historically possible" (a sense that we would want to specify further if this idea is to do serious normative work). On this sort of issue, see Davidson (2001), Hacking (2002), and Foucault (1984C). 
the above auxiliary topics I just mentioned might support taking a stronger line on the particular import of conceptual history, but I am not committed to any of them here..$^{2}$

\section{Reasons to Engage (or Disengage) in an Instance (or Kind) of Inquiry}

As I emphasized in Section 3, my core argument for the relevance of conceptual history to a given instance (or, similarly, kind) of inquiry rests on the idea that we have good normative reason to be engaged in that inquiry. If we did not, then we would lack good normative reasons to accomplish the constitutive aims of that inquiry, and, hence, its internal success-conditions wouldn't be ones that we should be much invested in. The questions of when and why one should engage in a given instance of inquiry (or, similarly, kind of inquiry) are complex normative questions - questions that are well beyond the scope of this paper. However, even without engaging with those questions, we can nonetheless identify things that plausibly would, other things being equal, give us important normative reasons to engage in that inquiry. At the same time, we can identify some things that, in one way or another, count significantly against our engaging in an inquiry: for example, by attenuating, undermining, or defeating our reasons for being engaged in it. In this section, I put forward a few broad proposals for what kinds of reasons support engaging in an inquiry, as well as what kinds of reasons count against doing so. I then explain how looking at conceptual history can help us realize we have such reasons. I thereby show how looking at conceptual history might not only contribute to helping us better meet the internal success-conditions of an inquiry, but also help us assess whether or not we should be engaged in that inquiry at all.

Here is a broad proposal for one important kind of reason that supports engaging in a given instance (or kind) of inquiry: engaging in it would help promote something that is ethically (or, relatedly, morally) valuable, e.g., happiness, well-being, or justice. And here is a connected proposal for one reason that supports not engaging in a given instance (or kind) of inquiry: it promotes things that are ethically bad (e.g., suffering or injustice), or, relatedly, hinders our ability to promote things that are valuable. Suppose these proposals are on the right track. One thing we might discover from conceptual history is that our use of certain concepts helps contribute to the promotion of certain things with ethical value (or, relatedly, of things with ethical disvalue). For example, we might

42. For an argument that the study of conceptual history can play certain important roles in conceptual ethics that cannot be played by inquiry into non-historical facts about concepts, see Epstein (2010). 
learn that the use of certain concepts has helped foster a more just social order. Such information will be helpful to have when considering what consequences our present (or future) use of these (or related) concepts is likely to have. The consequences of the use of concepts (in a given context) might not be at all obvious, and might be tied in subtle ways to ideology and the legitimation of unjust existing social structures. 43

This point is tied to an idea that runs through much of the work of Nietzsche, Max Weber, the Frankfurt School, and also Foucault. All of them argue, in one way or another, for a version of the following claim: the deployment of certain concepts (e.g., ones involving rationality, reason, the self, democracy, or liberty) that we might think of as relatively innocent, or even tied to a project of emancipation and the promotion of a better social order, might in practice actually be tied to maintaining forms of domination, subordination, or oppression. 44 Whether that is true or not for a given concept (or set of concepts) is, of course, a matter of actual conceptual history. And what to do about it, if true for a given concept (or set of concepts), will then raise complicated questions in conceptual ethics. For example, we can ask whether we should reform or replace the concepts, or whether we should instead continue to use the concepts but in ways that emphasize how their deployment until now has fallen short of the normative ideals that they themselves contain, or which they implicate in some basic way. ${ }^{45}$ But these are all downstream issues. For my purposes here, the key point is just this: conceptual history, by giving us information about the actual practical effects of the deployment of certain concepts, can be relevant to helping us figure out what reasons we have for engaging in a given instance (or kind) of inquiry, or for abandoning it. ${ }^{46}$

43. For more on this broad theme, see Haslanger (2005). Haslanger pursues this kind of project with respect to race and gender concepts, and concepts about social identity and social kinds more generally. Haslanger explicitly bases her approach in a kind of content externalism. As my way of putting things above is meant to underscore, one need not endorse any kind of externalism in order to pursue the basic kind of investigation I have in mind here, namely, one of studying the actual social effects of concept use (including, crucially, in the pursuit of a kind of ideology critique). Whether or not one endorses a form of externalism will, as Haslanger argues, have an effect on how this kind of study will proceed. But, crucially, endorsing a form of externalism is not a prerequisite for the broad kind of study I am glossing here.

44. See Nietzsche (1887/1994), Weber (1958), Habermas (1975), Horkheimer and Adorno (1947/2002), Marcuse (1964/1991), Foucault (1975/1995), and Foucault (1984b). (1984).

45. For discussion of versions of this last option, see both Foucault (1984b) and Habermas

46. As I explained earlier in this paper, the promotion of such ethical values might be tied to the internal success-conditions of a given kind of inquiry. (For example, this is so on certain ways of understanding the nature and aims of critical theory.) It should be emphasized that the above point is a different one. It is that information about the promotion of things that are ethically valuable can be relevant to all-things-considered questions about whether to engage in a given kind of inquiry, regardless of what the internal success-conditions of that inquiry are. (The same goes 
Here is another way in which conceptual history can help on this front. In some cases, the normative reasons we have for engaging in a given instance (or kind) of inquiry rest on certain key presuppositions. For example, suppose the internal success-conditions of a given kind of inquiry involve achieving a correct representation of the $X$ facts. Our normative reasons for engaging in that kind of inquiry might thus depend heavily on the presupposition that there are $\mathrm{X}$ facts. But perhaps there are no such $X$ facts. In such a case, some of our core normative reasons for engaging in that inquiry might be undercut. Conceptual history has the potential to help defeat such presuppositions, and thus to undercut our normative reasons for engaging in a given instance (or kind) of inquiry.

To illustrate how this might go, suppose we take it that the internal successconditions of normative inquiry involve learning about the normative facts. Suppose we then discover that a group of concepts emerged for reasons that had nothing at all to do with tracking the normative facts, or that our subsequent use of those concepts has not helped us better learn about normative facts. Nietzsche is plausibly read as holding that one or both of these claims are true of the specifically moral concepts (or at least a set of moral concepts that was prevalent during his time). As I glossed at the start of this paper, on one way of reading Nietzsche, the specifically moral concepts emerged as part of an attempt by some people to seek vengeance on others, rather than because people were tracking the normative facts. Since then, he claims, our use of those concepts has not helped us better grasp any important facts. Rather, he claims, the primary upshot of their use has been to stifle human flourishing (or, more precisely, the flourishing of a particular kind of person for whom Nietzsche has particular concern). If such a story is right, it might give us reason to doubt that there is an actual set of factsor, put another way, a subject matter - that those moral concepts are helping us understand. Indeed, if such a story is right, it might lead us to suspect that the concepts in question (namely, the moral concepts) aren't really helpful tools for understanding a subject matter at all, but rather essentially ideological tools of legitimation. We might then conclude, to put it in Nietzsche's own terms (from Twilight of The Idols), that we have become "stuck in a cage, imprisoned among all sorts of terrible concepts" (1889/1954: 502). If that radical conclusion is right, this might well give us reason to stop using those concepts and seek other ones to use instead when engaged in normative inquiry.

The broadly Nietzschean-style story here, of course, becomes more radical the more normative concepts it is used to cover. On the most radical end of the spectrum, one might seek to push it to cover all normative concepts-including those we use in epistemology, the parts of ethics outside of morality (parts that

for information about the promotion of things that are ethically bad, or that hinder our ability to promote things that are good.) 
Nietzsche himself seems to be relying on when he advocates views of human flourishing), or the philosophy of science. If so, this could lead us to be skeptical that there is a subject matter for any normative inquiry to be about in the first place. What should we make of such forms of radical skepticism? If my above line of argument is correct, what we should say depends in part on what the facts of conceptual history here actually are. (It depends, of course, on other things too, including, crucially, what the constitutive aims of normative inquiry are in the first place, and, in a connected vein, what presuppositions are built into our reasons for engaging in that inquiry.)

\section{Conclusion}

In this paper, I have sought to establish the following basic idea: conceptual history can matter for normative inquiry. I have argued for this claim in a way that aims to be highly ecumenical, and congenial to a wide range of philosophers working within the main currents of contemporary Anglo-American philosophy. I made this case in the following basic way: I argued that conceptual ethics matters for all forms of inquiry and that conceptual history can help us when we engage in conceptual ethics. I then argued that normative inquiry is a kind of inquiry, and, thus, that conceptual history can matter for normative inquiry.

Most philosophers working on normative issues don't have explicit developed views on the relevance or irrelevance of conceptual history to their work. Rather, mostly what happens is that philosophers simply hold unarticulated views on this topic and then use them in practice. If my arguments in this paper are on the right track, then philosophers engaged in normative inquiry shouldn't dismiss facts about the emergence of and past use of concepts as epistemically irrelevant in virtue of their being historical facts of this sort. Such facts can matter for normative inquiry. If this is right, it will require many of those engaged in normative inquiry to change their implicit working attitudes toward conceptual history. In short, it means having a more open mind than many currently do about the possibility of conceptual history mattering to what they are doing.

But what about someone engaged in addressing a specific normative question? How much does conceptual history matter then? My paper does not settle such questions. Rather, it gives us a schematic framework that helps us think about the kinds of conditions under which one kind of information (descriptive information about the emergence and past use of concepts) can be relevant to those engaged in normative inquiry. How much facts of conceptual history ultimately matter for normative inquiry, relative to other kinds of facts, is not something that my argument aims to settle. Nor does it aim to settle how conceptual history bears on particular normative questions. And how could it, given the 
kind of abstract issue that my argument is about? Nonetheless, my framework does help us get a better sense of what kinds of questions we should ask in assessing the relevance of conceptual history to particular normative issues. We should ask, among other things, what the constitutive aims of the relevant kind of inquiry actually are, what facts are relevant to settling the issues of conceptual ethics on the table, and also what the facts of conceptual history actually are. In other words, my argument not only gives us a better understanding of how and why conceptual history can bear on normative inquiry, but also helps provide the foundation for further investigation into how much it in fact matters for particular normative issues.

One upshot of my framework is that such investigation into the actual impact of conceptual history on particular normative issues, or on normative inquiry in general, is not going to be easy or straightforward. Figuring out the actual conceptual history of different concepts requires hard work. So too is hard work required to make progress on the sorts of foundational philosophical issues that I have argued matter for thinking about the relevance of conceptual history to normative inquiry, but which I have only briefly touched on here. These include issues about the aims of inquiry, issues about the foundations and nature of conceptual ethics, and the cluster of epistemological issues at the center of debates about peer disagreement and evolutionary debunking arguments. This, however, seems to me to be exactly the right result. Given our current epistemic situation, philosophers engaged in normative inquiry would do well to have an open mind about the potential relevance of conceptual history to their work-or at least a more open mind than many practitioners of normative inquiry currently do. But we should also not expect easy answers to what exactly the relevance of conceptual history to normative inquiry will amount to. To have that sort of expectation, in the context of our current epistemic situation, would involve a failure to appreciate the complexity and richness of the subject matter at hand.

\section{Acknowledgements}

Thanks to Amy Allen, Elizabeth Anderson, Nancy Bauer, Mario Biagioli, Sarah Bittman, Simon Blackburn, David Braddon-Mitchell, Ingo Brigandt, Alexis Burgess, Mark Budolfson, Daniela Cammack, Herman Cappelen, Victor Caston, Matthew Chrisman, Terence Cuneo, Stephen Darwall, Arnold Davidson, Tyler Doggett, Andrea Dolcetti, Kenny Easwaran, Dan Edelstein, James Edwards, Andy Egan, Brian Epstein, Björn Eriksson, Peter Galison, Eduardo GarciaRamirez, Allan Gibbard, Jonathan Gingerich, Raymond Geuss, Bob Goodin, Peter Gordon, Alex Gourevitch, Mark Greenberg, Patrick Greenough, David Grewal, Sally Haslanger, Burke Hendrix, Daniel Herwtiz, Nadeem Hussain, Henry 
Jackman, Frank Jackson, Lina Jansson, Matt Jones, Jim Joyce, Richard Joyce, Michelle Kosch, John Ku, John Kulvicki, Kevin Lamb, Kevin Lande, Alex Langlinais, Mika LaVaque-Manty, Shen-Yi Liao, Hallie Liberto, Brian Leiter, Sam Levey, Dustin Locke, Brett Lockspeiser, Kate Manne, Ben McKean, Tristram McPherson, Alison McQueen, Santiago Mejia, Eliot Michaelson, Jim Moor, Gilad Nir, Daniel Nolan, Howard Nye, Jonas Olson, Katherine Park, Robert Pasnau, Philip Pettit, Adam Plunkett, Peter Railton, Aziz Rana, Mark Richard, Jessica Rosenberg, Timothy Rosenkoetter, Paolo Santorio, Jennifer Saul, Karl Schafer, Kevin Scharp, Lea Schroeder, Mark Schroeder, Josh Schechter, Mira Siegelberg, Alex Silk, Dan Singer, Patrick Singy, Sharon Street, Tim Sundell, Patrick Tomlin, Sabine Tsuruda, Richard Tuck, Moisés Vaca Paniagua, Laura Valentini, Katia Vavova, Pekka Väyrynen, Kenny Walden, Caroline West, Stephen White, Gabriel Zamosc-Regueros, the anonymous referees who reviewed this paper, and the editors of Ergo. Earlier versions of this paper were presented at a conference on Conceptual Engineering at the Center for the Study of Mind in Nature (CSMN) at the University of Oslo in January 2015, the Summer Philosophy Workshop at the University of Stockholm in June 2013, the Ethics Working Group at the University of Vermont in April 2013, the UCLA Ethics Workshop in April 2012, the Social/Political Theory Colloquium at Australian National University in June 2009, and a conference on Historical Epistemology at Columbia University in October 2008. Thanks to everyone who participated in discussion at those presentations.

\section{References}

Adams, Zed (2016). On the Genealogy of Color: A Case Study in Historicized Conceptual Analysis. Routledge.

Anscombe, G. E. M. (1958). Modern Moral Philosophy. Philosophy, 33(124), 1-19. http:// dx.doi.org/10.1017/So031819100037943

Arato, Andrew and Eike Gephardt (Eds.) (1982). The Essential Frankfurt School Reader. Continuum.

Brandom, Robert (1994). Making it Explicit: Reasoning, Representing, and Discursive Commitment. Harvard University Press.

Burge, Tyler (1979). Individualism and the Mental. Midwest Studies in Philosophy, 4(1), 73-121. http://dx.doi.org/10.1111/j.1475-4975.1979.tboo374.x

Burgess, Alexis and David Plunkett (2013a). Conceptual Ethics I. Philosophy Compass, 8(12), 1091-1101. http://dx.doi.org/10.1111/phc3.12086

Burgess, Alexis, and David Plunkett (2013b). Conceptual Ethics II. Philosophy Compass, 8(12), 1102-1110. http://dx.doi.org/10.1111/phc3.12085

Christensen, David and Jennifer Lackey (2013). The Epistemology of Disagreement: New Essays. Oxford University Press. http://dx.doi.org/10.1093/acprof:o so/9780199698370.001.0001 
Clarke-Doane, Justin (2012). Morality and Mathematics: The Evolutionary Challenge. Ethics, 122(2), 313-340. http://dx.doi.org/10.1086/663231

Daston, Lorraine and Peter Galison (2007). Objectivity. Zone Books (MIT).

Davidson, Arnold I. (2001). The Emergence of Sexuality: Historical Epistemology and the Formation of Concepts. Harvard University Press.

Dworkin, Ronald (2011). Justice for Hedgehogs. Harvard University Press.

Enoch, David (2011). Taking Morality Seriously: A Defense of Robust Realism. Oxford University Press. http://dx.doi.org/10.1093/acprof:oso/9780199579969.001.0001

Epstein, Brian (2010). History and the Critique of Social Concepts. Philosophy of the Social Sciences, 40(1), 3-29. http://dx.doi.org/10.1177/0048393109350678

Foucault, Michel (1966/2002). The Order of Things. Routledge.

Foucault, Michel (1975/1995). Discipline and Punish: The Birth of the Prison (2nd ed.). Vintage Books.

Foucault, Michel (1978). The History of Sexuality (Vol. 1). Pantheon Books.

Foucault, Michel (1984a). Nietzsche, Genealogy, History. In Paul Rabinow (Ed.), The Foucault Reader (76-100). Pantheon Books.

Foucault, Michel (1984b). What is Enlightenment? In Paul Rabinow (Ed.), The Foucault Reader (32-50). Pantheon Books.

Foucault, Michel (1984C). On the Genealogy of Ethics: An Overview of Work in Progress. In Paul Rabinow (Ed.), The Foucault Reader (340-372). Pantheon Books.

Geuss, Raymond (1981). The Idea of a Critical Theory: Habermas and the Frankfurt School. Cambridge University Press.

Geuss, Raymond (1999). Morality, Culture, and History: Essays on German Philosophy. Cambridge University Press.

Geuss, Raymond (2001a). History and Illusion in Politics. Cambridge University Press.

Geuss, Raymond (2001b). Public Goods, Private Goods. Princeton University Press.

Geuss, Raymond (2008). Philosophy and Real Politics. Princeton University Press. http:// dx.doi.org/10.1515/9781400835515

Habermas, Jürgen (1975). Legitimation Crisis. Beacon Press.

Habermas, Jürgen (1984). The Theory of Communicative Action (Vols. 1-2). Beacon Press.

Hacking, Ian (2002). Historical Ontology. Harvard University Press. http://dx.doi. org/10.1007/978-94-017-0475-5_13

Haslanger, Sally (2000). Gender and Race: (What) Are They? (What) Do We Want Them to Be? Noûs, 34(1), 31-55. http://dx.doi.org/10.1111/0029-4624.00201

Haslanger, Sally (2005). What Are We Talking About? The Semantics and Politics of Social Kinds. Hypatia, 20(4), 10-26. http://dx.doi.org/10.1111/j.1527-2001.2005.tboo533.x

Haslanger, Sally (2012). Resisting Reality: Social Construction and Social Critique. Oxford University Press. http://dx.doi.org/10.1093/acprof:oso/9780199892631.001.0001

Hegel, Georg Wilhelm Friedrich (1807/1977). Phenomenology of Spirit. Clarendon Press.

Heidegger, Martin (1927/1962). Being and Time. John Macquarrie and Eric Robinson (Trans). Harper and Row Publishers.

Heidegger, Martin (1954/1993). The Question Concerning Technology. In David F. Krell (Ed.), Basic Writings. Harper Collins Press.

Horkheimer, Max (1937/1975). Traditional and Critical Theory. In Critical Theory: Selected Essays (188-243). Continuum.

Horkheimer, Max and Theodor W. Adorno (1947/2002). Dialectic of Enlightenment: Philosophical Fragments. Stanford University Press. 
Jackson, Frank (1998). From Metaphysics to Ethics: a Defence of Conceptual Analysis. Clarendon.

Joyce, Richard (2001). The Myth of Morality. Cambridge University Press. http://dx.doi. org/10.1017/cbo9780511487101

Koselleck, Reinhart (2002). The Practice of Conceptual History: Timing History, Spacing Concepts. Stanford University Press.

Kripke, Saul (1980). Naming and Necessity. Harvard University Press.

Leiter, Brian (2002). Routledge Philosophy Guidebook to Nietzsche on Morality. Routledge.

Locke, Dustin (2014). Darwinian Normative Skepticism. In Michael Bergmann and Patrick Kain (Eds.), Challenges to Moral and Religious Belief: Disagreement and Evolution (220-236). Oxford University Press. http://dx.doi.org/10.1093/acprof:o so/9780199669776.003.0012

MacIntyre, Alasdair C. (1984). After Virtue: A Study in Moral Theory (2nd ed.). University of Notre Dame Press.

Marcuse, Hebert (1964/1991). One-Dimensional Man: Studies in the Ideology of Advanced Industrial Society. Beacon Press.

Margolis, Eric and Stephen Laurence (1999). Concepts: Core Readings. MIT Press.

Marx, Karl and Freidrich Engels (1978). The Marx-Engels Reader. Robert C. Tucker (Ed.). Norton.

Moyn, Samuel (2012). The Last Utopia: Human Rights in History. Belknap (Harvard University Press).

Nehamas, Alexander (1985). Nietzsche: Life as Literature. Harvard University Press.

Nietzsche, Friedrich Wilhelm (1887/1994). On the Genealogy of Morality. Cambridge University Press.

Nozick, Robert (1974). Anarchy, State, and Utopia. Basic Books.

Parfit, Derek (1984). Reasons and Persons. Clarendon Press.

Putnam, Hilary (1975). The Meaning of 'Meaning'. Minnesota Studies in the Philosophy of Science 7, 131-193. http://dx.doi.org/10.1017/cbo9780511625251.014

Schafer, Karl (2010). Evolution and Normative Scepticism. Australasian Journal of Philosophy, 88(3), 471-488. http://dx.doi.org/10.1080/00048400903114219

Scharp, Kevin (2013). Replacing Truth. Oxford University Press. http://dx.doi.org/10.1093/ acprof:0so/9780199653850.001.0001

Schroeter, Laura (2008). Why Be an Anti-Individualist? Philosophy and Phenomenological Research, 77(1), 105-141. http://dx.doi.org/10.1111/j.1933-1592.2008.00178.x

Setiya, Kieran (2012). Knowing Right from Wrong. Oxford University Press. http://dx.doi. org/10.1093/acprof:0so/9780199657452.001.0001

Sider, Theodore (2012). Writing the Book of the World. Oxford University Press.

Skinner, Quentin (1978). The Foundations of Modern Political Thought (Vols 1-2). Cambridge University Press.

Skinner, Quentin (2002). Visions of Politics (Vols. 1-3). Cambridge University Press.

Street, Sharon (2006). A Darwinian Dilemma for Realist Theories of Value. Philosophical Studies, 127(1), 109-166. http://dx.doi.org/10.1007/s11098-005-1726-6

Tuck, Richard (1993). Philosophy and Government, 1572-1651. Cambridge University Press. http://dx.doi.org/10.1017/cbo9780511558634

van Fraassen, Bas C. (1980). The Scientific Image. Oxford University Press. http://dx.doi. org/10.1093/0198244274.001.0001

Vavova, Katia (2014). Debunking Evolutionary Debunking. In Russ Shafer-Landau 
(Ed.), Oxford Studies in Metaethics Vol. 9, (76-101). http://dx.doi.org/10.1093/acprof:o so/9780198709299.003.0004

Väyrynen, Pekka (2013). The Lewd, the Rude and the Nasty: A Study of Thick Concepts in Ethics. Oxford University Press. http://dx.doi.org/10.1093/acprof:o so/9780199314751.001.0001

Weber, Max (1958). From Max Weber: Essays in Sociology. Oxford University Press.

Williams, Bernard (1985). Ethics and the Limits of Philosophy. Harvard University Press.

Williams, Bernard (2002). Truth and Truthfulness: An Essay in Genealogy. Princeton University Press.

Wolterstorff, Nicholas (2008). Justice: Rights and Wrongs. Princeton University Press. http://dx.doi.org/10.1515/9781400828715 